\title{
The Relative Age Effect on Athletes of the Santa Catarina Basketball Federation
}

\author{
Larissa F. P. Maciel' , Alexandra Folle' ${ }^{1}$ Mônica C. Flach', Sara C. Silva', Walan R. da Silva', Mariana K. Beirith'1, \\ Carine Collet $^{1}$
}

Affiliations: 'Santa Catarina State University (UDESC), Health and Sport Sciences Center (CEFID), Santa Catarina, Brazil

Correspondence: L. F. P. Maciel, Santa Catarina State University, Health and Sport Sciences Center, 358 Pascoal Simone Street, Coqueiros, Florianopolis, Brazil. Email: larissa.maciel10@edu.udesc.br

\begin{abstract}
This study analyses the relative age effect (RAE) in basketball athletes, considering the categories (U13, U15, U17, and U19), sex, number of games and average points. The participants were 1,455 Brazilian athletes aged between 9 and 19 who participated in the Santa Catarina State Basketball Championship in the 2018 season. To test the $R A E$, the Chi-square test ( $x 2$ ) was performed to compare the observed distribution and expected birth quartiles. To verify the differences between the birth quartiles concerning the average of points and the number of games, One-Way ANOVA with post hoc Bonferroni was applied. The effect size was verified using Eta ${ }^{2}$. Odds Ratios and confidence intervals were calculated for all birth quartiles. In conclusion, it was found that, in the general sample of players participating in the Santa Catarina State Basketball Championship, there was an over-representation of players born in the first two quarters of the year in most of the categories analysed. However, significant differences were found in the number of games and average points only in male players in the U13 category. These results confirm that the player selection process is negatively biased towards boys born at the end of the year in the U13 category.
\end{abstract}

Keywords: relative age effect, youth sport, athlete development, birthday distribution

$@$ @JSSMontenegro

RELATIVE AGE EFFECT ON ATHLETES

http://mjssm.me/?sekcija=article\&artid=228

Cite this article: Maciel, L.F.P., Folle, A., Flach, M.C., Silva, S.C., da Silva, W.R., Beirith, M.K., \& Collet, C. (2022). The Relative Age Effect on Athletes of the Santa Catarina Basketball Federation. Montenegrin Journal of Sports Science and Medicine, 11 (1), 29-35. https://doi.org/10.26773/mjssm.220303

\section{Introduction}

Performance in basketball, as in other sports, is influenced by several individual (date of birth, maturation) and environmental (sports system and culture) factors (Hancock et al., 2013). In several modalities, sports categories are composed by the grouping of athletes by annual age groups established by sports organizations (Lago-Fuentes et al., 2020). The well-intentioned objective is to provide equal opportunities and competition (Huertas et al., 2019; Lupo et al., 2019). However, there may be a difference (chronological and biological) of up to 12 months between children and adolescents born in the same year (Lago-Fuentes et al., 2020) and of up to 24 months for those who participate in competitions composed of players born in two consecutive years (Saavedra \& Saavedra, 2020; Ibáñez et al., 2018). Such differences play a fundamental role in the level of development of athletes, consequently influencing their sports performance in the early stages of sports training.

The age difference between individuals in a given group the Creative Commons Attribution (CC BY).

Conflict of interest: None declared. 
concerning a cut-off point is known as Relative Age. In contrast, this difference can produce the potential advantage known as the Relative Age Effect (RAE) (Saavedra \& Saavedra, 2020). In this case, the RAE is associated with the participation and performance advantages of chronologically older athletes concerning younger athletes within the same age category due to their greater physical, cognitive, and emotional development (Sierra-Díaz et al., 2017; Ibáñez et al., 2018). Thus, in the early stages of sport development, older athletes tend to have more excellent representation and the possibility of accessing environments that improve their skills (Saavedra \& Saavedra, 2020; Oliveira et al., 2019).

On the international scene, investigations aimed at understanding the RAE in the representation of basketball athletes in youth competitions have revealed a better representation of athletes born in the first months of the year (Vegara-Ferri et al., 2019; Ibañez et al., 2018; Torres -Unda et al., 2016), especially in the initial categories. In contrast, studies carried out with athletes from adult categories have not found significant differences between the months of the year and the representation of athletes born in the first or last months of the year (Vegara-Ferri et al., 2019; Esteva et al., 2006; Baker et al., 2009). Such studies reinforce the evidence that RAE is more highly prevalent in youth teams (Jackson \& Comber, 2020; Ibáñez et al., 2018) than in adult teams (Brustio et al., 2018; Doyle \& Bottomley, 2019).

The results found in most international research corroborate the inference that the selection (representation) of basketball athletes based on advantages related to dates of birth are smoothed or eliminated when players reach full maturation in late adolescence (Ibañez et al., 2018). However, research carried out in Spanish elite basketball found that RAE is present in professional teams due to the selection of athletes born in the first quarters of the year (with superior maturation and physical development) during the training period. (Esteva et al., 2006).

Concerning the performance of athletes in disputed competitions, García et al. (2014) found minor variations, although these differences did not coincide with the existence of RAE. As for sex, Arrieta et al. (2015) and Brazo-Sayareda et al. (2018) found a higher prevalence of RAE in male athletes compared to females. These results reinforce the finding that RAE is highly prevalent in male athletes, especially when the sport demands are physical and high in popularity and a high level of competitive selection among teams is present (Brazo-Sayareda et al., 2018). In contrast, Leite et al. (2013) did not find significant RAE values related to the sex of the athletes.

Brazilian studies carried out with youth athletes present evidence similar to those found in the international literature. The results have shown a better representation of athletes born in the first months of the year and a more significant presence of RAE in male than female athletes (Oliveira; Ribeiro Júnior; Vianna et al., 2017; Oliveira; Ribeiro Júnior; Werneck et al., 2017). These data corroborate the indication by Arrieta et al. (2015) that, in a sporting season, athletes who matured earlier have advantages in sports performance. Oliveira, Ribeiro Júnior, Vianna et al. (2017) highlight that the selection of athletes based on physical aspects related to performance and the grouping of players into age categories with an age difference of up to 24 months is the primary responsibility for RAE in competitions for young athletes, especially in Brazil.

A study carried out with athletes who competed in the ma- jor Brazilian adult competitions showed the presence of the RAE, but in an inverted form in athletes aged 25 to 34 years and the absence of the effect for those who were in the final phase of their career (Oliveira et al., 2019). For Oliveira et al. (2019, p. 7), the inversion of RAE in athletes who are in the consolidation phase in Brazilian basketball (higher proportion in the 3rd quartile) may "[...] be associated with a compensatory effect of technical, tactical and psychological skills that were not developed in athletes born in the first months of the year". That indicates that many athletes who reach this stage of career development have disabilities that do not allow them to remain at the highest level of their adult careers. Furthermore, the finding of maintenance of the RAE in adult competitions corroborates the indication of Esteva et al. (2006) that this is a consequence of the previous selection carried out in the training categories.

Based on the theoretical support presented, very few publications focused on the RAE on Brazilian athletes from training categories (Oliveira; Ribeiro Júnior; Vianna et al., 2017), primarily encompassing athletes participating in all youth competitions of federation state sports. Furthermore, we do not know of studies that analysed this theme, relating the representativeness of athletes born at different times of the year with participation in games and the average of points converted in the games played. In this scenario, this study aimed to analyse the relative age effect in basketball athletes, considering the categories (U13, U15, U17, U19), sex, number of games and average points.

\section{Methods \\ Study design and participants}

This study is characterized as cross-sectional. A total of 1.455 Brazilian athletes aged between 9 and 19 years (14.37 \pm 2.0 years) participated in the research. Of these, 503 were female, and 952 were male, who participated in the Santa Catarina State Basketball Championship (Brazil) in the 2018 season. State championships (U13 to U19) are organized by the Santa Catarina Basketball Federation (FCB) and involve basketball clubs from all six Santa Catarina/Brazil regions. Phases organize the competitions: qualifying (turn and return, classifying eight teams); semi-final (octagonal, all against all, classifying four teams); and final (foursquare all against all). It is noteworthy that the FCB, among the federations affiliated to the Brazilian Basketball Confederation (CBB), stands out with a consolidated federation, which annually holds regional, state and interstate tournaments, in addition to participating (with significant results) in national competitions promoted by CBB (FCB, 2019, 2020). In 2018, 43 teams participated in these competitions, in categories U13 ( $\mathrm{n}=588$ athletes), U15 ( $\mathrm{n}=435$ athletes), U17 ( $\mathrm{n}=264$ athletes $)$ and U19 $(\mathrm{n}=$ 168 athletes). Some investigated athletes who participated in competitions in categories above their age, but these athletes were analysed only in their category of origin (relative to their chronological age).

\section{Data collection procedures}

Information was obtained from three document sources. Information regarding the sex and date of birth was obtained from the FCB's official website (https://www.basket-fcb.com. $\mathrm{br} /$ ). The tabulation of these data was carried out between March and September 2019. The information regarding the number of games played and the athletes' scores in compe- 
titions was tabulated between June and December 2019, obtained from the match summaries provided by the president of the FCB, as they were not available on the federation's official website. Informed consent or approval from the Ethics Committee was not required to carry out the study, as it is public domain data accessible online (Maciel et al., 2021; Saavedra \& Saavedra, 2020). In addition, there is no explicit or implicit prohibition on that website that would make the use of data for academic and scientific purposes unfeasible. Nevertheless, all data were treated together, without reference to the names of teams and players.

\section{Statistical Analyses}

To test the RAE, the Chi-square test $(\chi 2)$ was performed to compare the observed and expected distribution in the birth quartiles (categorized by the athletes' birth quarter - Q1: January to March, Q2: April to June, Q3: July to September, Q4: October to December and by sex (female and male)). Expected frequencies were based on the birth rate evenly distributed throughout the year. This choice was made due to the difficulty accessing birth statistics for each population studied (Cobley et al., 2009). Sharpe (2015) suggested that the standardized residual was also calculated and interpreted as significant when greater than $\mathrm{z}>|2.0|$. To verify the differences between the birth quartiles concerning the average of points and the number of games, One-Way ANOVA with post hoc Bonferroni was applied. The effect size was verified using Eta ${ }^{2}$. All tests were performed using the IBM SPSS 20.0 software (Inc, Chicago, IL, USA), and the significance level was set at $\mathrm{p}<0.05$. Odds Ratios (ORs) and confidence intervals were calculated for all birth quartiles, considering the categories (U13, U15, U17 and U19) of both sexes.

\section{Results}

Figure 1 shows the distribution of athletes into birth quartiles according to sex. Differences were found in the birth quartile of athletes of both sexes in the U13 category. The standardized residuals showed significant results in the last birth quartile of the female U13 category $(\mathrm{z}=-2.6)$, showing a birth frequency of athletes below expectations. In contrast, in the male U13 category, the results were significant in the first three birth quartiles $(\mathrm{z}=8.2 ; \mathrm{z}=7.2 ; \mathrm{z}=5.6)$, revealing a frequency of athletes higher than expected. In the U15 and U19 categories, the RAE was found only in male athletes. More athletes were born in the first two quartiles of the year, except for female U19 athletes.
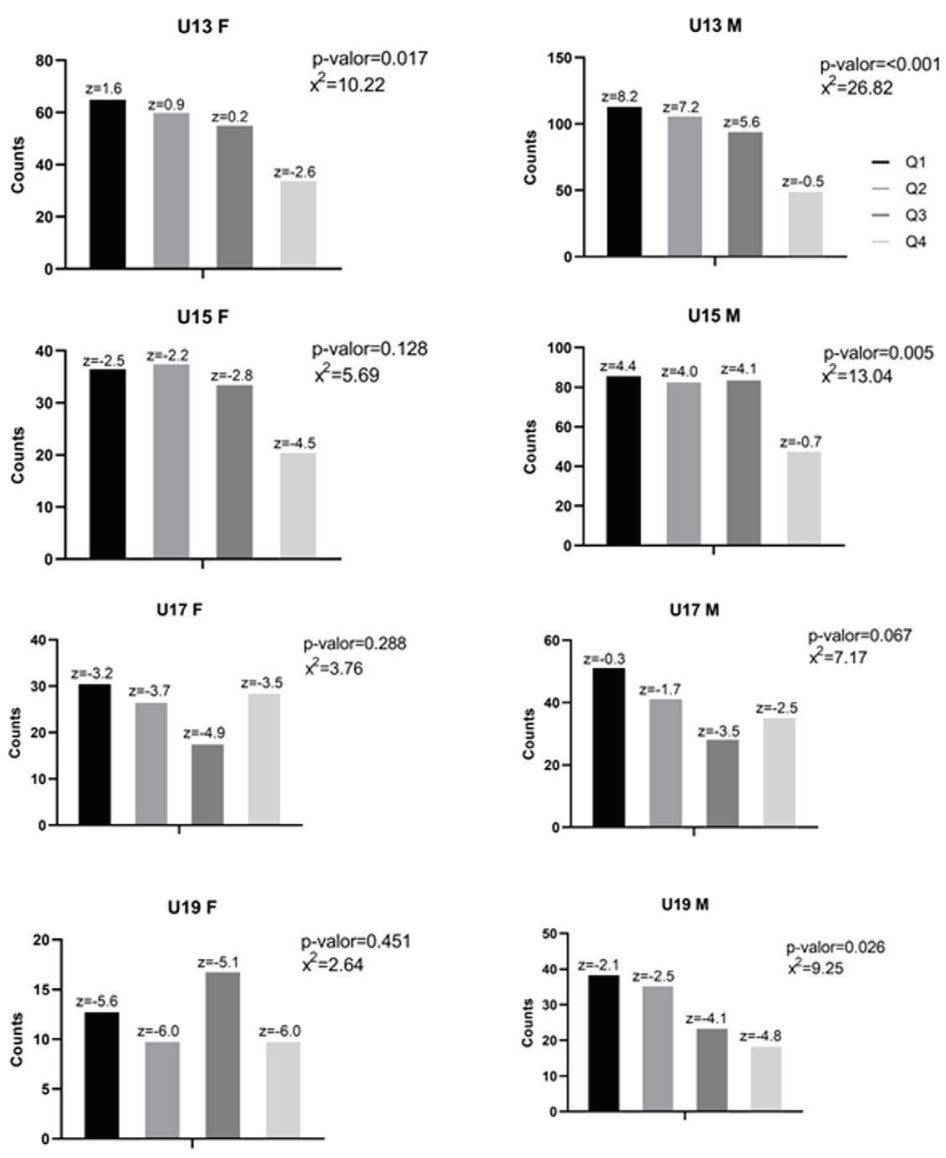

Figure 1. Relative age effect in relation to a category according to sex. $\mathrm{F}=$ female; $\mathrm{M}$ = male; $\mathrm{Q} 1-\mathrm{Q} 4$ = birth quarter; $\mathrm{X} 2$ = Chi-square; $\mathrm{Z}=$ Std. Residual.

The comparison between the number of games per birth quarter, according to category and sex, is shown in Table 1. Athletes aged up to 13 years, born in the first months of the year, participated in more games than younger athletes within the same age category $(\mathrm{p}=0.033)$. The results were not signifi- cant in the other categories. However, from the U15 category onwards, there is a tendency for athletes born in the last quarter of birth to be equivalent or even to perform a more significant number of games than older athletes, revealing a decrease in the RAE concerning the number of games played. 
Table 1. Comparison between the number of games per quarter of birth, by category and sex

\begin{tabular}{|c|c|c|c|c|c|c|c|c|}
\hline & Q1 & Q2 & Q3 & Q4 & Total & $\mathrm{F}$ & Sig. & $\mathrm{Eta}^{2}$ \\
\hline \multicolumn{9}{|l|}{ U13 } \\
\hline Female & $6.94(3.54)$ & $6.84(3.52)$ & $6.54(3.52)$ & $6.31(3.19)$ & $6.71(3.46)$ & 0.320 & 0.811 & 0.067 \\
\hline Male & $7.23(3.58)$ & $7.08(2.87)$ & 6.74 (3.39) & $5.67(3.15)$ & $6.84(3.30)$ & 2.934 & 0.033 & 0.153 \\
\hline \multicolumn{9}{|l|}{ U15 } \\
\hline Female & $5.08(2.99)$ & $5.97(2.89)$ & $6.12(3.16)$ & $7.10(3.85)$ & $5.94(3.19)$ & 1.880 & 0.136 & 0.207 \\
\hline Male & $4.38(2.04)$ & 4.05 (1.94) & $4.18(2.07)$ & $3.76(2.13)$ & $4.13(2.04)$ & 1.043 & 0.374 & 0.101 \\
\hline \multicolumn{9}{|l|}{ U17 } \\
\hline Female & $5.87(3.22)$ & $6.37(3.18)$ & $6.61(2.91)$ & $5.66(3.30)$ & $6.07(3.16)$ & 0.457 & 0.713 & 0.116 \\
\hline Male & 7.87 (3.94) & $7.93(2.87)$ & 7.38 (3.69) & $6.86(3.57)$ & $7.57(3.55)$ & 0.765 & 0.515 & 0.121 \\
\hline \multicolumn{9}{|l|}{ U19 } \\
\hline Female & $4.08(2.29)$ & $4.10(2.76)$ & $4.29(2.33)$ & $5.10(1.91)$ & $4.36(2.30)$ & 0.442 & 0.724 & 0.164 \\
\hline Male & $6.82(3.89)$ & $5.81(2.66)$ & $5.96(4.07)$ & $6.84(3.23)$ & $6.34(3.48)$ & 0.751 & 0.524 & 0.139 \\
\hline
\end{tabular}

Note. Q1-Q4 = birth quarter; Sig. = significance; Eta2 = eta squared.

Table 2 shows the comparison between mean points and birth trimester, considering the category and sex of the athletes. There is a significant association only in the U13 category $(\mathrm{p}<0.05)$ male. In other words, older athletes have a higher average of points compared to younger athletes. Although not significant, this trend persists in the other male categories, while in the U15 and U19 women's categories, younger athletes have a higher average score than older athletes.

Table 2. Comparison between the average of points per quarter of birth, by category and sex

\begin{tabular}{|c|c|c|c|c|c|c|c|c|}
\hline & Q1 & Q2 & Q3 & Q4 & Total & $\mathrm{F}$ & Sig. & $\mathrm{Eta}^{2}$ \\
\hline Female & $4.02(5.10)$ & $3.48(4.73)$ & $2.54(6.17)$ & $3.06(4.43)$ & $3.33(5.20)$ & 0.863 & 0.461 & 0.106 \\
\hline Male & $4.92(6.06)$ & 3.38 (3.79) & $3.75(4.46)$ & $1.76(2.55)$ & $3.73(4.75)$ & 5.725 & 0.001 & 0.212 \\
\hline \multicolumn{9}{|l|}{ U15 } \\
\hline Male & $4.87(5.76)$ & $5.17(5.85)$ & $4.52(5.97)$ & $3.22(3.76)$ & 4.59 (5.59) & 1.355 & 0.257 & 0.115 \\
\hline \multicolumn{9}{|l|}{ U17 } \\
\hline Female & $5.48(6.02)$ & $4.63(4.74)$ & $4.17(4.28)$ & $4.69(5.04)$ & $4.82(5.11)$ & 0.284 & 0.837 & 0.092 \\
\hline Male & $5.29(5.13)$ & $5.31(5.62)$ & $4.48(4.79)$ & $5.14(4.95)$ & $5.11(5.12)$ & 0.184 & 0.907 & 0.06 \\
\hline
\end{tabular}

The results of the ORs are shown in Table 3. The sample did not reveal significant ORs for all comparisons.

Table 3. Unadjusted odds ratios (ORs) according to the RAE in the category

\begin{tabular}{cccc}
\hline & \multicolumn{3}{c}{ OR comparisons $(95 \% \mathrm{Cl})$} \\
\cline { 2 - 4 } U13 & Q1 vs Q4 & Q2 vs Q4 & Q3 vs Q4 \\
\cline { 2 - 4 } U15 & $0.78(0.69-1.97)$ & $1.23(0.72-2.11)$ & $1.25(0.72-2.15)$ \\
U17 & $0.71(0.40-1.45)$ & $1.09(0.63-1.90)$ & $1.20(0.68-2.10)$ \\
U19 & $0.62(0.25-1.41)$ & $0.66(0.37-1.18)$ & $0.51(0.27-1.93)$ \\
\hline
\end{tabular}

Note. $\mathrm{Q} 1-\mathrm{Q} 4$ = birth quarter; $\mathrm{OR}=$ chance ratio; $\mathrm{Cl}=$ confidence interval.

\section{Discussion}

Similar to previous studies that analysed the presence of RAE in young players, we observed a higher proportion of athletes born in the first two quarters of the year (Ibáñez et al., 2018; Torres-Unda et al., 2016; Vegara-Ferri et al., 2019). However, it is noteworthy that some substantial differences were found mainly in the U13 category and among male athletes.
The U13 is characterized as one of Brazil's first competitive basketball categories for athletes up to 13 years old. In this category, players usually have their first contact with formal games and competitions and experience competitive experiences. However, the search for immediate success arising from strategic and organizational factors of clubs and training centres (De Bosscher \& De Rycke, 2017; Ribeiro Júnior et 
al., 2019) has resulted in a phenomenon called "maturation selection", in which chronologically older players are chosen because of their superior physical, anthropometric, and performance qualities (Campos et al., 2020) compared to younger players.

Our results are consistent with the results found by Ribeiro Júnior et al. (2020), who also found the presence of RAE in basketball players in the initial categories (U12, U13), with a more significant number of individuals born in the first and second trimester of the year. According to Oliveira et al. (2019), this more significant representation of players born in the first months of the year is more evident in younger categories, when athletes have wider biological and maturational variability. However, our evidence does not corroborate other studies that found the RAE in the U15 and U17 categories of basketball teams participating in the Brazilian Club Championship (CBC) (Oliveira, Ribeiro Júnior, Vianna, et al., 2017; Oliveira, Ribeiro Júnior, Werneck, et al., 2017) and U17 and U19 of the world's elite teams of the sport (Vegara-Ferri et al., 2019).

In the RAE and the number of games played and in the average of points, the differences were more significant in boys from the U13 category. The results found in the study with athletes who participated in the $\mathrm{CBC}$ revealed that high stature players in the U13 category surpassed the average height of the U14 category players (Ribeiro Júnior et al., 2020). Thus, even though the players' body size was not inferred in this study, it can be said that because the differences in body height concerning the quarter in which the player was born are even more visible in the younger categories, taller players in the basketball is more likely to hit the basket and, consequently, score more points during matches (Rubajczyk et al., 2017), leading them to be called up for more games.

In a study carried out with French basketball players aged eight to 18 years, evidence showed that those born in the first semester of the year had greater body height in all categories when compared to their younger peers (Delorme \& Raspaud, 2009). Similarly, evidence found in the study carried out with Polish athletes showed that U14 players born in the first months of the year have greater body height and better performance than younger players within the same category (Rubajczyk et al., 2017). Therefore, players matured earlier, especially when the biological and maturational transformations inherent in the transition from childhood to adolescence are more prevalent, are generally taller, more muscular and demonstrate more refined abilities and skills than younger players within the same age category (Campos et al., 2020).

In this study, significant differences were found mainly among male Brazilian players. According to Lidor et al. (2014), one reason why the RAE is superior in male players is the imbalance in the number of players, teams, and popularity of basketball nationwide between the sexes. This statement has been confirmed in Brazilian studies, firstly due to the absence of an intermediate national championship between the U17 and adult female category for an extended period (Oliveira, Ribeiro Júnior, Werneck, et al., 2017), and secondly, due to the difference in the number of male (79) versus female (52) teams enrolled in the State Championship of Santa Catarina in the year in which the information for this study was collected. However, this finding is specific to the Brazilian context and cannot be generalized to other countries.

In the female categories, RAE was present only in U13 players, confirming evidence from other studies that reduced the effect in older female categories (Ferreira et al., 2020; Rubajczyk et al., 2017; Sierra-Díaz et al., 2017). In addition to the prevalence of a more significant number of male athletes, differences in the distribution of birth dates and body height of basketball players are less visible than in boys, as puberty dynamics differ between the sexes (Brazo-Sayavera et al., 2018; Rubajczyk et al., 2017). Thus, it is necessary to create solutions to minimize the presence of the RAE as a function of sex in youth basketball (Rubajczyk et al., 2017), favouring equality of participation and competition in the sport.

Concerning the number of games and the average of points, different results were found by Arrieta et al. (2015) in the study carried out with elite basketball players from the Spanish league, which found the RAE in players from the older categories (U16, U18, U20), who had a long time of participation in games, higher number of points and superior performance level when compared to younger players. The Brazilian categories U15, U17 and U19 did not show significant differences in the number of games and average points, demonstrating a more homogeneous pattern in players' performance in these categories, which is the opposite of what was seen in the study of the Spanish players.

According to Jackson and Comber (2020), the RAE loses strength as athletes approach the adult categories, and the representation of players based on advantages related to birth dates are smoothed or eliminated when youngsters reach full maturation in late adolescence (Arrieta et al., 2015; Ibáñez et al., 2018). In this case, the influence of relative age differences that benefited those born at the beginning of the year tends to decrease as players mature mentally and physically (Rubajczyk et al., 2017).

For this reason, there must be a sporting process designed and executed in the long term, as the players who stand out in the initial categories will not always be the same ones who will remain prominent in the adult categories. Previous studies have observed that younger players (born closer to the deadline) have longer professional careers when compared to their older peers. (Lago-Fuentes et al., 2020; Rubajczyk \& Rokita, 2018).

Finally, it should be noted that the selectivity around players considered talented who matured earlier can increase the dropout rate of young players born in the last months of the year. Therefore, training and competition opportunities must be ample and favour the permanence of young people, especially in the initial categories, without the early selection processes causing losses and consequent abandonment of sports practice.

It is believed that, regardless of the month of birth and sex, all athletes should have equal opportunities for sports development because the more comprehensive the practice opportunities, the greater the chances of long-term sporting success, whether in the sport of high performance or participation sport for life. Therefore, only a longitudinal approach, which consists of monitoring athletic performance throughout the athlete's entire sports career, would be able to confirm whether the RAE is prevalent in all categories and provides better performance over time, favouring those who are more biologically advanced, who have advantages, often temporary, concerning other (Ribeiro Júnior et al., 2019).

This work has several limitations. First, only the number of games and the average points of the games were considered 
for analysis. Other physical (speed, skill) and anthropometric (weight, height) variables could contribute to a greater understanding of the effects of the RAE on Brazilian players. Secondly, this study concerns only analysing the distribution of birth dates in youth basketball, without considering the adult male and female categories. Finally, only one sporting season was considered; the monitoring of several competitive seasons could add important information about the RAE relationship with the performance of athletes over time.

In conclusion, it was found that there was an over-representation (RAE) of players born in the first two quarters of the year in most of the categories analysed in the general sample of players participating in the Santa Catarina State Basketball Championship. However, we found significant differences in the number of games and average points only in male U13 players. These results confirm that the player selection process is negatively biased towards boys born at the end of the year in U13.

\section{Acknowledgements}

This study was financed in part by the Coordenação de Aperfeiçoamento de Pessoal de Nível Superior - Brazil (CAPES) - Finance Code 001. Thanks are due to the Santa Catarina Federation of Basketball (FCB) for making the data available, and to the members of Laboratório de Pesquisa em Práticas Pedagógicas da Educação Física (LAPRAPEF) for their assistance and participation in the current research.

\section{References}

Arrieta, H., Torres-Unda, J., Gil, S. M., \& Irazusta, J. (2015). Relative age effect and performance in the U16, U18 and U20 European Basketball Championships. Journal of Sports Sciences, 34(1), 1530-1534. https://doi.org/10.1080/ 02640414.2015 .1122204

Brazo-Sayavera, J., Martínez-Valencia, M. A., Müller, L., Andronikos, G., \& Martindale, R. J. J. (2018). Relative age effects in international age group championships: A study of Spanish track and field athletes. PLoS ONE, 13(4). https://doi.org/10.1371/journal.pone.0196386

Brustio, P. R., Lupo, C., Ungureanu, A. N., Frati, R., Rainoldi, A., \& Boccia, G. (2018). The relative age effect is larger in Italian soccer top-level youth categories and smaller in Serie A. PLoS ONE, 13(4), e0196253. https://doi. org/10.1371/journal.pone.0196253

Campos, F. A. D., Pellegrinotti, Í. L., Campos, L. C. B., Dias, T. M. R., \& Gómez, M. Á. (2020). Relative Age Effect in the Girls' Volleyball U18 World Championship. Journal of Human Kinetics, 72(1), 195-202. https://doi.org/10.2478/ hukin-2019-0106

Cobley, S., Baker, J., Wattie, N., \& McKenna, J. (2009). Annual Age-Grouping and Athlete Development. Sports Medicine, 39(3), 235-256. https://doi.org/10.2165/00007256200939030-00005

De Bosscher, V., \& De Rycke, J. (2017). Talent development programmes: a retrospective analysis of the age and support services for talented athletes in 15 nations. European Sport Management Quarterly, 17(5), 590-609. https://doi.org/10 $.1080 / 16184742.2017 .1324503$

Delorme, N., \& Raspaud, M. (2009). The relative age effect in young French basketball players: A study on the whole population. Scandinavian Journal of Medicine and Science in Sports, 19(2), 235-242. https://doi.org/10.1111/j.16000838.2008.00781.x

Donald, S. (2015). Your chi-square test is statistically significant: Now what? Practical Assessment. Research and Evaluation, 20(8), 1-10.

Esteva, S., Drobnic, F., Puigdellivol, J., Serratosa, L., \& Chamorro, M. (2006). Fecha de nacimiento y éxito en el baloncesto profesional. Apunts Medicina de l'Esport, 41(149), 25-30. https://doi.org/10.1016/S18866581(06)70004-4

Ferreira, S. A., Do Nascimento, M. A., Cavazzotto, T. G., Reis Weber, V. M., Tartaruga, M. P., \& Queiroga, M. R. (2020). Relative age in female futsal athletes: Implications on anthropometric profile and starter status. Revista Brasileira de Medicina Do Esporte, 26(1), 34-38. https:// doi.org/10.1590/1517-869220202601189174

García, M. S., Aguilar, Ó. G., Romero, J. J. F., Lastra, D. F., \& Oliveira, G. E. (2014). Relative age effect in lower categories of international basketball. International Review for the Sociology of Sport, 49(5), 526-535. https://doi. org/10.1177/1012690212462832

Hancock, D. J., Adler, A. L., \& Côté, J. (2013). A proposed theoretical model to explain relative age effects in sport. European Journal of Sport Science, 13(6), 630-637. https:// doi.org/10.1080/17461391.2013.775352

Ibáñez, S. J., Mazo, A., Nascimento, J., \& García-Rubio, J. (2018). The Relative Age Effect in under-18 basketball: Effects on performance according to playing position. PLoS ONE, 13(7). https://doi.org/10.1371/journal.pone.0200408

Jackson, R. C., \& Comber, G. (2020). Hill on a mountaintop: A longitudinal and cross-sectional analysis of the relative age effect in competitive youth football. Journal of Sports Sciences, 38(11-12), 1352-1358. https://doi.org/10.1080/0 2640414.2019.1706830

Lago-Fuentes, C., Rey, E., Padrón-Cabo, A., Prieto-Troncoso, J., \& Garcia-Núñez, J. (2020). The Relative Age Effect in Professional Futsal Players. Journal of Human Kinetics, 72(1), 173-183. https://doi.org/10.2478/hukin-2019-0105

Leite, N., Borges, J., Santos, S., \& Sampaio, J. (2013). The relative age effect in school and federative sport in basketball. Revista de Psicología Del Deporte, 22(1), 219-223.

Lidor, R., Arnon, M., Maayan, Z., Gershon, T., \& Côté, J. (2014). Relative age effect and birthplace effect in Division 1 female ballgame players-the relevance of sport-specific factors. International Journal of Sport and Exercise Psychology, 12(1), 19-33. https://doi.org/10.1080/161219 7X.2012.756232

Lupo, C., Boccia, G., Ungureanu, A. N., Frati, R., Marocco, R., \& Brustio, P. R. (2019). The beginning of senior career in team sport is affected by the relative age effect. Frontiers in Psychology, 10(June), 1-6. https://doi.org/10.3389/ fpsyg.2019.01465

Maciel, L. F. P., Flach, M. C., Krapp Do Nascimento, R., Dallegrave, E. J., Nascimento, J. V. do, \& Folle, A. (2021). Relative Age Effect on basketball: implications for the selection of successful players. RETOS, 42, 266-275. https://recyt.fecyt.es/index.php/retos/index

Oliveira, H. Z., Ribeiro Júnior, D. B., Vianna, J. M., \& Werneck, F. Z. (2017). Efeito da idade relativa no campeonato Brasileiro de basquete: Categoria sub-15. Revista Brasileira de Cineantropometria e Desempenho Humano, 19(5), 526534. https://doi.org/10.5007/1980-0037.2017v19n5p526 
Oliveira, H. Z., Ribeiro Júnior, D. B., Vianna, J. M., Figueiredo, A. J., \& Werneck, F. Z. (2019). O que realmente importa para chegar ao alto nível: uma abordagem do efeito da idade relativa no basquetebol brasileiro. Journal of Physical Education, 30, 3079. https://doi.org/10.4025/jphyseduc. v30i1.3079

Oliveira, H. Z., Ribeiro Júnior, D. B., Werneck, F., \& Tavares, F. (2017). Efeito da idade relativa nos jogadores do campeonato brasileiro de basquete da categoria sub-17. Revista Portuguesa de Ciências Do Desporto, 17(1), 90-98. https://doi.org/10.5628/rpcd.17.S1A.90

Ribeiro Júnior, D. B., Lobão, P. H. F., Oliveira, H. Z., Viana, J. M., \& Werneck, F. Z. (2020). O efeito da idade relativa em indivíduos normoestaturais e de elevada estatura no basquetebol de base do Brasil. E-Balonmano.Com: Revista de Ciencias Del Deporte, 16(1), 1-10.

Ribeiro Júnior, D. B., Vianna, J. M., Lauria, A. de A., Coelho, E. F., \& Werneck, F. Z. (2019). Sports potential modeling of young basketball players: A preliminary analysis. Revista Brasileira de Cineantropometria e Desempenho Humano, 21. https://doi.org/10.1590/1980-0037.2019v21e59832

Rubajczyk, K., \& Rokita, A. (2018). The Relative Age Effect in Poland's Elite Youth Soccer Players. Journal of Human Kinetics, 64(1), 265-273. https://doi.org/10.1515/ hukin-2017-0200
Rubajczyk, K., Świerzko, K., \& Rokita, A. (2017). Doubly disadvantaged? The relative age effect in Poland's basketball players. Journal of Sports Science and Medicine, 16(2), 280-285.

Saavedra, Y., \& Saavedra, J. M. (2020). The Association between Relative Age Effect, Goals Scored, Shooting Effectiveness and the Player's Position, and her Team's Final Classification in International Level Women's Youth Handball. Montenegrin Journal of Sports Science Medicine, 9(1), 1-7. https://doi.org/10.26773/mjssm.200303

Sierra-Díaz, M., González-Víllora, S., Pastor-Vicedo, J., \& Serra-Olivares, J. (2017). Soccer and Relative Age Effect: A Walk among Elite Players and Young Players. Sports, 5(1), 5. https://doi.org/10.3390/sports5010005

Torres-Unda, J., Zarrazquin, I., Gravina, L., Zubero, J., Seco, J., Gil, S. M., Gil, J., \& Irazusta, J. (2016). Basketball performance is related to maturity and relative age in elite adolescent players. Journal of Strength and Conditioning Research, 30(5), 1325-1332. https://doi.org/10.1519/ JSC.0000000000001224

Vegara-Ferri, J. M., García-Mayor, J., Pérez, A. M., \& Cabezos, H. (2019). Relative age effect in the basketball world championships sub-17, sub-19 and Olympic games of Brazil 2016. Journal of Sport and Health Research, 11(1), 33-42. 